was limited to one interview or occasionally two. Their prognosis tended to be worse than that of more intensively treated patients (Tables I and IV), and our results indicate that many of the patients who had only brief psychiatric contact subsequently benefited from further psychiatric treatment (Table II). The specific characteristics of patients who benefit mostand least-from psychiatric treatment will be described in a subsequent paper (Bagley and Greer, 1971).

It was surprising to discover that more than one-fifth of the present series had no psychiatric contact whatsoever following their suicidal attempt. In most cases these patients were sent home because the casualty officer considered that there was no medical danger and the suicidal attempt was therefore a trivial matter. Our findings indicate that this assumption is both mistaken, since the degree of medical danger was not related to prognosis, and dangerous, since $39 \%$ of untreated patients made further suicidal attempts and $4.5 \%$ killed themselves within 18 months. These results lend force to the Central Health Services Council's (1968) recommendations: "All cases of deliberate self-poisoning should be referred to a designated poisoning centre, regardless of the seriousness or otherwise of their medical condition ... they should never be sent home without undergoing psychiatric assessment."

The present study shows that psychiatric treatment was associated with a significant fall in incidence of subsequent suicidal attempts. Since untreated patients are particularly liable to repeat suicidal attempts, and since multiple suicidal attempts increase the probability of eventual suicide (Ettlinger, 1964), it seems likely that adequate facilities for psychiatric treatment could save lives as well as reduce the repeat rate for parasuicide.

We thank the patients whose co-operation made this study possible; Professor J. Anderson and Dr. D. Liddell for their encouragement; and Mr. I. Corkindale, who searched the General Register Office records for death entries. The study was generously supported by King's College Hospital Medical School research funds.

Requests for reprints should be addressed to Dr. S. Greer, King's College Hospital, London, S.E.5.

\section{References}

Aitken, R., Buglass, D., and Kreitman, N. (1969). British fournal of Preventive and Social Medicine, 23, 111.

Bagley, C. (1968). Social Science and Medicine, 2, 1.

Bagley, C. (1968). Social Science and Medicine, 2, 1.

Bagley, C. (1971). Social and Economic Administra

Central Health Services Council (1968). Hospital Treatment of Acute Poisoning. London, H.M.S.O.
Health Services Council

Ettlinger, R. (1964). Acta Psychiatrica Scandinavica, 40, 363.

Greer, S., and Lee, H. (1967). Acta Psychiatrica Scandinavica, 43, 361.

Kessel, N. (1966). Fournal of Psychosomatic Research, 10, 29.

Kessel, N., and McCulloch, W. (1966). Proceedings of the Royal Society of Medicine, 59, 89.

Kreitman, N., Philip, A., Greer. S., and Bagley, C. (1969). British fournal of Psychiatry, 115, 746 .

Ministry of Health (1961). H.M. (61). 94.

Roberts, J., and Hooper, D. (1969). British fournal of Medical Psychology, 42, 303 .

Ruegsegger, P. (1963). Psychiatria et Neurologia, 146, 81.

Schmidt, E., O'Neal, P., and Robins, E. (1954). Fournal of the American Medical Association, $155,549$.

Walk, A. (1967). British Fournal of Psychiatry, 113, 1381.

\title{
Prevention of Postoperative Deep Venous Thrombosis and Pulmonary Embolism
}

\author{
A. E. CARTER, R. EBAN, R. D. PERRETT
}

British Medical fournal, 1971, 1, 312-314

\section{Summary}

Two series of patients observed clinically and by phlebography suggest that one agent known to produce a reduction in platelet aggregation in vitro might be useful in reducing the incidence of deep venous thrombosis and pulmonary embolism postoperatively. The agent used in this study was hydroxychloroquine sulphate.

\section{Introduction}

Postoperative lower limb venous thrombosis causes discomfort, delay in discharge from hospital, and disability that may last throughout life. Moreover, it is believed to be the precedent to pulmonary embolism, an event responsible for death in as few as $6 \%$ and, possibly, as many as $28 \%$ of hospital deaths (Morrell and Dunhill, 1968), all of which are, at least in theory, preventable. The incidence of venous thrombosis

King Edward Memorial Hospital, London W.13 A. E. CARTER, F.R.C.S., Consultant Surgeon R. EBAN, M.R.C.P., F.F.R., Consultant Radiologist

R. D. PERRETT, F.R.C.S., Surgical Registrar (at present Senior Surgical Registrar, Prince Henry Hospital, Little Bay, N.S.W., Australia) in various series of patients ill enough to be in hospital or subjected to surgery varies widely, depending on the criteria used to make the diagnosis; the more accurate the diagnosis the higher the rate-from $8 \%$ (Stadil, 1968) to $83 \%$ (Sevitt and Innes, 1964). Negus and Pinto (1968) suggested that in people over the age of 50 years undergoing major surgery the rate may be as high as $34 \%$.

The observation by Payling Wright (1941) that, in association with surgical procedures, the platelets' capacity to adhere together is increased has stood the test of repeated proof. Aggregation of platelets as a precedent to thrombosis may possibly be a not dissimilar process from the red cell "sludging" that occurs in trauma and infection as described by Knisely et al. (1941). Madow (1960) showed that red cell "sludging" could be reduced by several antimalarial agents, and he reported, in particular, the effect of hydroxychloroquine sulphate in this respect. It seemed possible, therefore, that hydroxychloroquine sulphate might reduce the propensity of platelets to adhere in traumatic situations and that, if it did without inducing a tendency to bleed or other complications, it might thereby reduce the incidence of deep venous thrombosis and pulmonary embolism in patients submitted to surgery.

The diagnosis of venous thrombosis solely by clinical signs is unreliable; phlebography is highly accurate and simple (Thomas, 1970). A combination of phlebography and clinical signs can serve as a guide to the effects of agents used to try to prevent thrombosis, and this report concerns one such agent investigated by these means. 


\section{Hydroxychloroquine and Platelet Aggregation}

Assessment of the effect of hydroxychloroquine sulphate on platelet aggregation was made by the method of Born and Cross (1963), adenosine diphosphate being the initiating agent. Platelet-rich plasma was obtained from ambulant patients free from infection and neoplastic disease who had not had surgery, by centrifugation of citrated whole blood at 1,000 r.p.m. for 15 minutes at $4-6^{\circ} \mathrm{C}$. The platelet-rich plasma was kept at this temperature during the assay. Optical density of the platelet-rich plasma was measured in a Unicam densitometer with white light at $600 \mu$ (red filter). The zero point was obtained with platelet-poor plasma from the same sample centrifuged at 5,000 r.p.m. for 30 minutes. Adenosine diphosphate was added to each sample as $0.1 \mathrm{ml}$ of a solution containing $134 \mathrm{mg}$ per litre $\left(2.5 \times 10^{-6} \mathrm{M}\right)$; hydroxychloroquine was added as $0.1 \mathrm{ml}$ of a solution containing $200 \mathrm{mg}$ per litre. Normal saline was added as appropriate in order to obtain the same volume in each sample.

Results.-The results obtained are shown in the Chart. Apart from one patient the addition of hydroxychloroquine caused a reduction in the rate of fall of density of between 33

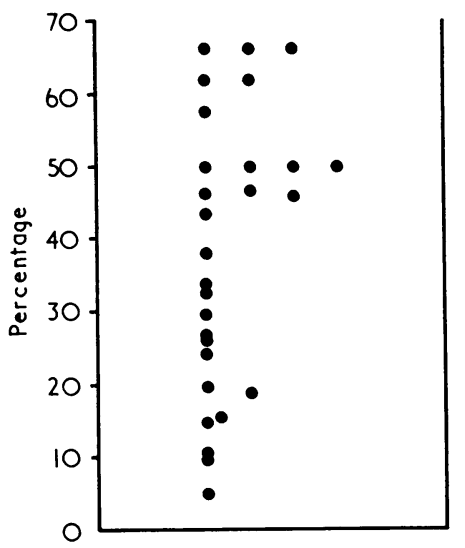

Percentage reduction of platelet aggregation by hydroxychloroquine sulphate.

and $98 \%$. The difference in the means of the control and treated samples is statistically significant $(\mathrm{P}<0.001)$.

\section{Clinical Studies}

Initial studies were made to determine the risk of oozing of blood at operation in patients given $200 \mathrm{mg}$ hydrochloroquine sulphate one hour before a wide variety of surgical procedures under the care of 10 consultants and their 12 registrars. There was no complaint of undue oozing, and 21 estimates of bleeding and clotting times on the same patients were all within normal limits.

Two series of patients were then studied: one a continuous series of ward patients in which clinical signs were used to diagnose thrombosis, the other in which phlebography was used. Both groups consisted of men and women over the age of 45 years who were to undergo major surgery (as defined in Statutory Instrument No. 420 of 1953). Allocation to treatment or control groups was by a predetermined random series: the treated group received $200 \mathrm{mg}$ hydrochloroquine sulphate by injection with their premedication and subsequently $200 \mathrm{mg}$ eight-hourly either by injection or orally until discharge from hospital. No patient was admitted to either group who had been confined to bed preceding operation (some patients were admitted up to five days preoperatively for investigation but were not confined to bed), who had active inflammation, or who had had a history of phlebitis, thrombosis, or pulmonary embolism.
A total of 565 patients were studied (304 men and 261 women); the criteria for the diagnosis of deep venous thrombosis in the calf were accepted as positive if two or more of the following signs were present: deep calf tenderness, positive Homan's sign, increased warmth and delayed cooling of the affected leg, a "spike" of fever, and local leg oedema. For pulmonary embolism two or more of the characteristic chest and pleuritic pain, radiological signs, blood-stained sputum, and E.C.G. changes were accepted criteria for making the diagnosis, sometimes with necropsy confirmation (in every fatal case in this series necropsy was performed).

Results.-The age and sex distribution of the series is shown in Table I; differences between and within the treatment groups in the proportion of patients in a given decennial age group are not significant. The control group has a sex ratio of 1.3:1.0 compared with $1: 1$ for the hydroxychloroquine group. This difference is not statistically significant. The operation and sex distributions are shown in Table II, in which, within each sex, differences between the treatment groups are not significant. Statistically fewer females underwent lower abdominal operations as compared with the males $(19 \%: 39 \%)$. The time in hospital preceding operation is shown in Table III; $64 \%$ of patients having their operations one day after admission, $10 \%$ waiting more than five days. The incidence of clinically apparent deep venous thrombosis in the series is shown in Table IV. There was none in the hydroxychloroquine group and 25 in the controls (9\%): a highly significant difference $(\mathrm{P}<0.001)$. The incidence of pulmonary embolism is shown in Table V; $6 \%$ in the controls and $1 \%$ in the hydroxychloroquine group, a highly significant difference $(\mathbf{P}<0.001)$.

\section{Fhlebography Series}

Fifty-two patients ( 27 men and 25 women) fitting the classes described above were submitted to bilateral lower-limb phlebography between the 6th and 11th days postoperatively. Their age and sex distribution is shown in Table VI. The

\begin{tabular}{|c|c|c|c|c|c|c|c|}
\hline \multirow{2}{*}{ Treatment } & \multirow{2}{*}{ Sex } & \multicolumn{5}{|c|}{ Age (years) } & \multirow{2}{*}{ Total } \\
\hline & & $45-54$ & $55-64$ & $65-74$ & $74+$ & N.S. & \\
\hline $\begin{array}{l}\text { Control } \\
\begin{array}{c}\text { Hydroxychloroquine } \\
\text { sulphate }\end{array}\end{array}$ & $\begin{array}{l}\text { M. } \\
\text { F. } \\
\text { M. } \\
\text { F. }\end{array}$ & $\begin{array}{l}32 \\
33 \\
31 \\
31\end{array}$ & $\begin{array}{l}57 \\
32 \\
54 \\
50\end{array}$ & $\begin{array}{l}50 \\
28 \\
37 \\
39\end{array}$ & $\begin{array}{l}21 \\
21 \\
19 \\
19\end{array}$ & $\begin{array}{l}1 \\
6 \\
2 \\
2 \\
\end{array}$ & $\begin{array}{l}161 \\
120 \\
143 \\
141 \\
\end{array}$ \\
\hline Total & & 127 & 193 & 154 & 80 & 11 & 565 \\
\hline
\end{tabular}

TABLE II-Operation and Sex Distribution

\begin{tabular}{|c|c|c|c|c|c|c|c|c|}
\hline \multirow{2}{*}{\multicolumn{2}{|c|}{ Treatment }} & \multirow{2}{*}{ Sex } & \multicolumn{5}{|c|}{ Operation } & \multirow{2}{*}{ Total } \\
\hline & & & $\mathbf{A}$ & B & C & D & $\mathbf{E}$ & \\
\hline $\begin{array}{l}\text { Control } \\
\text { Hydroxychloroquine } \\
\text { sulphate }\end{array}$ & \{ & $\begin{array}{l}\mathbf{M} . \\
\mathbf{F} \\
\mathbf{M} . \\
\mathbf{F} .\end{array}$ & $\begin{array}{l}72 \\
44 \\
53 \\
60\end{array}$ & $\begin{array}{l}64 \\
21 \\
56 \\
28\end{array}$ & $\begin{array}{l}\overline{23} \\
1 \\
23\end{array}$ & $\begin{array}{l}17 \\
25 \\
20 \\
27\end{array}$ & $\begin{array}{r}8 \\
7 \\
13 \\
3\end{array}$ & $\begin{array}{l}161 \\
120 \\
143 \\
141\end{array}$ \\
\hline Total & 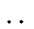 & & 229 & 169 & 47 & 89 & 31 & 565 \\
\hline
\end{tabular}

$A=$ Upper abdominal. $B=$ Lower abdominal, perineal, or renal. $C=$ Mastectomy $\mathrm{D}=$ Laparotomy. E = Other (vaginal repair, hysterectomy, transurethral prostati resection,
tomy).

TABLE III-Distribution of Interval between Admission and Operation

\begin{tabular}{|c|c|c|c|c|c|c|c|c|c|c|}
\hline \multirow{2}{*}{ Treatment } & \multirow{2}{*}{ Sex } & \multicolumn{8}{|c|}{ Interval (days) } & \multirow{2}{*}{ Total } \\
\hline & & $<1$ & 1 & 2 & 3 & 4 & 5 & $5+$ & N.S. & \\
\hline $\left.\begin{array}{ll}\text { Control } & \ldots \\
\text { Hydroxychloroquine } \\
\text { sulphate }\end{array}\right\}\{$ & $\begin{array}{l}\mathbf{M} . \\
\mathbf{F} \\
\mathbf{M} \\
\mathbf{F}\end{array}$ & $\begin{array}{l}8 \\
5 \\
2 \\
4\end{array}$ & $\begin{array}{r}100 \\
66 \\
103 \\
91 \\
\end{array}$ & $\begin{array}{l}11 \\
11 \\
11 \\
20\end{array}$ & $\begin{array}{l}3 \\
8 \\
3 \\
7\end{array}$ & $\begin{array}{r}14 \\
11 \\
6 \\
5\end{array}$ & $\begin{array}{l}\mathbf{4} \\
\mathbf{5} \\
\mathbf{8} \\
\mathbf{3}\end{array}$ & $\begin{array}{l}20 \\
14 \\
10 \\
11 \\
\end{array}$ & $\frac{1}{-}$ & $\begin{array}{l}161 \\
120 \\
143 \\
141 \\
\end{array}$ \\
\hline Total & & 19 & 360 & 53 & 21 & 36 & 20 & 55 & 1 & 565 \\
\hline
\end{tabular}


TABLE IV-Distribution of Occurrence of Thrombosis

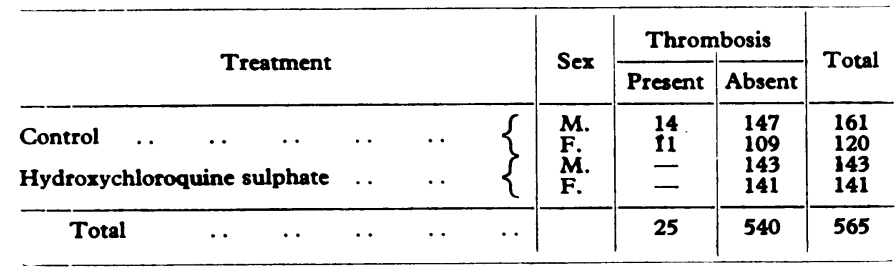

TABLE V-Distribution of Occurrence of Pulmonary Embolism

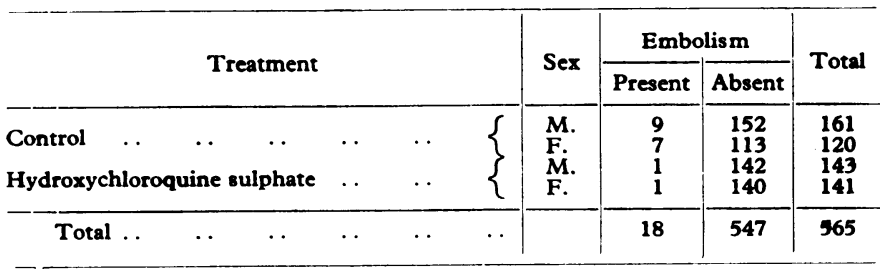

TABLE VI-Age and Sex Distribution (Phlebography series)

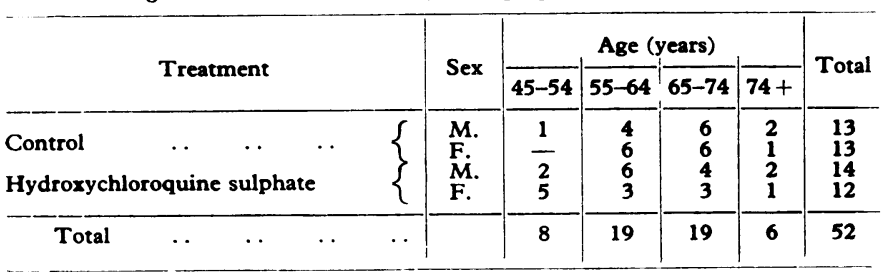

TABLE VII-Distribution of Type of Operation (Phlebography series)

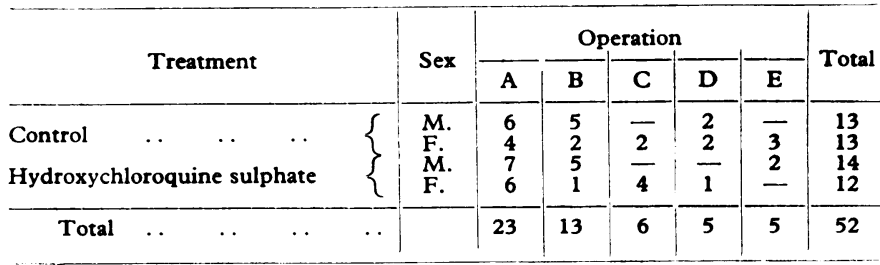

$A=$ Upper abdominal. $B=$ Lower abdominal. $C=$ Mastectomy. $D=$ "Laparotomy." $\mathrm{A}=$ Upper abdominal. $\mathrm{B}=$ Lower abdominal.
$\mathrm{E}=$ "Other," including hiatus hernia repairs.

TABLE VIII-Distribution of Occurrence of Thrombosis (Phlebography series)

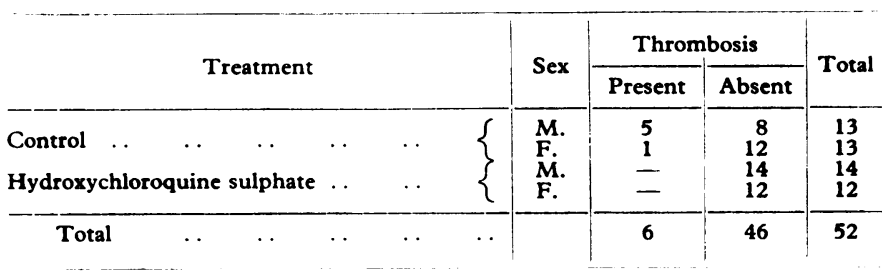

overall sex ratio is 1.1:1.0 with almost identical within-treatment ratios: no statistically significant differences are found in the between-treatment distribution of ages. Type of operation distribution is shown in Table VII. There is a weighting in favour of mastectomy among the women but no statistical differences otherwise in the distributions. Half had their venograms on the sixth day, $35 \%$ on the ninth day, and the remainder on the 10 th or 11 th day postoperatively. The incidence of clots shown by the phlebograms is given in Table VIII.

There were no cases of thrombosis in those patients who received hydroxychloroquine, but 6 cases $(23 \%)$ were observed in the control group. The proportion of males with clots in the control group, $5 / 13$, is significantly different from the corresponding proportion in the hydroxychloroquine group, $0 / 14(P<0.02)$. The female distribution is similar. Combining the sexes produces a statistically significant difference between treatment groups $(\mathrm{P}<0.05)$.

\section{Discussion}

Having determined that hydroxychloroquine sulphate reduces platelet aggregation in vitro, we made a study to assess its usefulness as an agent to reduce the incidence of lower-limb venous thrombosis and consequent pulmonary embolism in the postoperative period. A series in which clinical signs only were used to make the diagnosis and another series in which phlebography was used tended to support the concept that agents producing a reduction in platelet aggregation might be useful in preventing deep venous thrombosis and pulmonary embolism without producing complications of their own.

Both groups reported here are small and only guarded support can be given to the proposition, especially in the light of the report by Browse and Hall (1969) on the apparently unsatisfactory effect of dipyridamole in this respect.

We are grateful to the Bayer Products Company for the supply of hydroxychloroquine sulphate as Plaquenil and the placebo and to Dr. L. Goldman and Dr. J. B. Spooner, of that company, for arranging the random series and for their extensive help and advice throughout the study.

Financial support was granted by the Bayer Products Company and the Hospital's Research Funds and, from private individuals through the help of the Hospital's League of Friends.

\section{References}

Born, G. V. R., and Cross, M. J. (1963). Fournal of Physiology, 168, 178 Browse, N. L., and Hall, J. H. (1969). Lancet, 2, 718.

Knisely, M. H., Strathman-Thomas, W. K., and Eliot, T. S. (1941). Fournal of the American Medical Association, 116, 2430

Lea, Thomas M. (1970). Proceedings of the Royal Society of Medicine, 63, 123.

Madow, B. P. M. (1960). Fournal of the American Medical Association, 172,

Morrell, M. T., and Dunhill, M. S. (1968). British fournal of Surgery, 55,

347.

Sevitt, S., and Innes, D. (1964). Lancet, 1, 124

Stadil, F. (1968). Acta Chirugica Scandinavica, Suppl. No. 387, p. 88.

Wright, H. Payling. (1941). fournal of Pathology and Bacteriology, 23, 255. 